\title{
OS DIREITOS DE ACESSOS EM MATÉRIA AMBIENTAL E SUA EFETIVIDADE: O MEIO AMBIENTE DIGITAL NO FUTURO ACORDO REGIONAL SOBRE O PRINCÍPIO 10
}

\author{
ACCESS RIGHTS IN ENVIRONMENTAL MATTERS AND ITS EFFECTIVENESS: THE DIGITAL \\ ENVIRONMENT IN THE FUTURE REGIONAL AGREEMENT ON PRINCIPLE 10
}

\author{
Enzo Bello ${ }^{1}$ \\ Giulia Parola ${ }^{2}$
}

Resumo: Com o presente artigo teve-se por objetivo apresentar e debater os chamados direitos de acessos em matéria ambiental, constantes do futuro Acordo Regional sobre o Princípio 10 da Declaração do Rio de Janeiro (sobre o acesso à informação, à participação e à justiça em matéria ambiental), que está sendo elaborada desde 2012 por países da América Latina e Caribe. Esse instrumento poderia, uma vez concluído e ratificado, ser um novo instrumento jurídico em proveito do exercício dos direitos humanos em matéria ambiental. A eficácia dos três pilares do futuro tratado pode ser expandida graças à revolução digital e à introdução de ferramentas virtuais. Por esse motivo o futuro Acordo já inclui nos seus artigos diferentes instrumentos digitais. $O$ presente texto foi elaborado a partir de pesquisa qualitativa, de perfil teórico-normativo, adotando o referencial teórico da Democracia Ambiental e utilizando como técnicas de pesquisa a análise documental e a revisão bibliográfica. As fontes primárias de pesquisa são documentos de Direito Ambiental no plano do Direito Internacional e Comunitário, especialmente os referentes ao meio ambiente digital. Como resultados parciais da pesquisa, considerando a previsão de aprovação do futuro Acordo Regional para o final do ano 2017, identifica-se um indicativo claro da formulação de um paradigma normativo e um referencial ético na construção de uma democracia ambiental na América Latina e no Caribe, bem como uma democracia ambiental digital que instituem novos direitos humanos e trazem os respectivos mecanismos de efetividade.

Palavras-chave: Direitos humanos. Direitos de acesso em matéria ambiental. Meio ambiente digital. Acordo Regional sobre o Princípio 10. Eficácia-efetividade.
Abstract: The objective of this article was to present and discuss the so-called environmental access rights, which are foreseen in the future Regional Agreement on Principle 10 of the Declaration of Rio de Janeiro (on Access to information, Participation and to Justice in Environmental Matters), which is being elaborated since 2012 by Latin American and Caribbean countries. This instrument could, once completed and ratified, be a new legal tool for the exercise of human rights in environmental matters. The effectiveness of the three pillars of the future treaty can be expanded by the digital revolution and by the introduction of virtual tools. For this reason the future agreement already includes in its articles different digital instruments. This paper was written from a qualitative research, with theoretical and normative profile, adopting the theoretical guidelines of Environmental Democracy, and using as research techniques documental analysis and bibliographical review. The primary research sources are documents from the Environmental Law in the field of International and Communitarian Law, especially those referring to digital environment. As partial results of the research, considering the prediction of the future Regional Agreement approval to the end of 2017, it is identified a clear indicative of the formulation of a normative paradigm and an ethical referential in the construction of an environmental democracy in Latin America and in the Caribbean Countries, as well as a digital environmental democracy, which institute new human rights and bring the respective mechanisms of effectiveness.

Keywords: Human rights. Environmental access rights. Digital environment. Regional Agreement on Principle 10. Efficacy-effectiveness.

\footnotetext{
Pós-Doutor em Direito pela Universidade do Vale do Rio dos Sinos; Doutor em Direito pela Universidade do Estado do Rio de Janeiro; Professor Adjunto III da Faculdade de Direito e do Programa de Pós-Graduação em Direito Constitucional da Universidade Federal Fluminense; enzobello@gmail.com

2 Pós-doutoranda pelo Programa de Pós-Graduação em Direito Constitucional da Universidade Federal Fluminense; Doutora em Direito Ambiental pela Université Paris V - René Descartes (França); Professora permanente do Programa de Pós-Graduação em Direito Constitucional da Universidade Federal Fluminense; giuliaparola.law@gmail.com
} 


\section{Introdução}

"Information generates knowledge and knowledge generates power." (KRAMER, 2004, p. 1).

Com a expansão das tecnologias da informação, especialmente da internet, a revolução digital constitui uma das maiores mudanças em nível global da época contemporânea e impacta as atividades das mais diversas sociedades. Ao menos duas consequências podem ser identificadas quanto a esse fenômeno que afetam o relacionamento entre os Estados e seus cidadãos.

Por um lado, a internet colocou nas mãos de uma parcela considerável da população mundial (SILVEIRA, 2001, p. 48-49) maior parte de poder mediante uma ferramenta que pode ser utilizada, entres outras finalidades, para controle do poder público, para organização e mobilização social e para acesso às informações em rede. Consequentemente, uma participação política mais intensa. Esse instrumento coloca em crise o clássico monopólio do controle da informação, que outrora foi exercido pela figura do monarca e mais recentemente pela do Estado. Efetivamente, podemos constatar que "as autoridades governamentais nunca estiveram tão passíveis de serem observadas e criticadas como hoje em dia" (MARTINS, 2015) e que, graças a isso, "o fosso diminuiu, e diminuiu muito" entre cidadãos e Estado (TAVARES; MARCACINI, 2015).

Por outro lado, uma segunda consequência da dita revolução digital é o "crescimento excepcional do volume e do tipo de dados existentes, que são produzidos em grande velocidade e de forma contínua por pessoas, máquinas e dispositivos, pelas negociações eletrônicas e pelo uso da internet, entre outras fontes." (BARCENA, 2015). A criação de um meio ambiente digital (RANGEL, 2017; FIORILLO; WALDMAN, 2016, p. 139; FIORILLO; MARTINEZ, 2015), resultante desse aumento dos dados virtuais, paralelamente tem gerado crescentes demandas dos cidadãos por informação de qualidade, que seja cada vez mais confiável, clara, aberta, atualizada e oportuna. Por esse motivo, faz-se necessário criar um sistema de acesso à informação "passiva" e "ativa" mais transparente, pois uma efetiva participação na vida social e política se desenvolve onde há um direito de acesso à informação passivo do cidadão e uma espontânea divulgação das informações pelo Estado.

A revolução tecnológica e digital e o meio ambiente digital conferem não somente essa oportunidade, mas também a de direcionar essas ferramentas para contribuir na defesa do meio ambiente (SAMPAIO, 2013, p. 14233-14298). Portanto, "pode favorecer o exercício direitos humanos em matéria ambiental, como a participação e informação" (FIORILLO; WALDMAN, 2016, p. 139) e o acesso à justiça. Ou seja, três direitos fundamentais complementares que podem gerar a efetivação concreta da defesa do meio ambiente.

Os direitos ambientais procedimentais na defesa do meio ambiente foram reconhecidos formalmente pela primeira vez na Declaração do Rio sobre Meio Ambiente e Desenvolvimento de 1992, em especial, no famoso Princípio 10. 
Em 2017, após 25 anos da sua afirmação, esse princípio assume uma amplitude maior, por ser imprescindível que os recursos digitais possam ser um instrumento para facilitar a implementação e a eficiência desses direitos de acesso. Além disso, o mundo digital pode tornar-se não somente um meio para facilitar o direito de acesso à informação, mas também uma nova ferramenta que facilite a participação dos cidadãos, conferindo-lhes maior possibilidade de se organizarem e participarem dos processos de tomadas de decisões. ${ }^{3}$ Enfim, os três direitos de acesso possuem também a capacidade de se tornar o eco das vozes e das populações mais desfavorecidas e marginalizadas e de facilitar o exercício dos direitos humanos em matéria ambiental.

O enfoque deste artigo vai nessa direção. $\bigcirc$ meio ambiental digital - ou seja, o conjunto de dados e informações criados por cidadãos e por autoridades públicas - é concebido aqui na sua natureza instrumental, como veículo de circulação rápida de informação, como ferramenta a serviço da tutela do meio ambiente, como meio para atingir resultados de justiça socioambiental e, enfim, como ferramenta de implementação dos direitos de acessos.

Por esse motivo, inicialmente será analisada, de forma breve, a primeira implementação em nível regional do Princípio 10, feita pela Convenção de Aarhus sobre Acesso à Informação, Participação do Público no Processo de Tomada de Decisão e Acesso à Justiça em Matéria de Ambiente de 1998. Em seguida será examinado o Futuro Acordo de implementação desse Princípio em âmbito regional na América Latina e Caribe ${ }^{4}$ enquanto na terceira parte serão exploradas as novidades da futura nova convenção em face do antigo Tratado, com foco nas ferramentas digitais do futuro Acordo, buscando entender as suas implicações no meio ambiente digital.

$O$ presente texto consiste em extrato de pesquisa em andamento, que tem natureza qualitativa e perfil teórico-normativo, adota o referencial teórico da Democracia Ambiental e utiliza como técnicas de pesquisa a análise documental e a revisão bibliográfica. As fontes primárias de pesquisa são documentos de Direito Ambiental no plano do Direito Internacional e Comunitário, especialmente os referentes ao meio ambiente digital.

\section{A origem dos "direitos de acessos" e a Convenção de Aarhus}

A concepção contemporânea dos direitos processuais, também chamados "de acessos", remonta à Declaração Universal dos Direitos do Homem de 1948 (ONU, 1948), que estipula que os cidadãos devem dispor de instrumentos que lhes permitam expressar as suas opiniões nas decisões

\footnotetext{
3 Ao mesmo tempo, assim como afirmam Fiorillo e Waldman (2016, p. 139), este instrumento: "pode ser utilizado pelo Poder Público para realizar consultas públicas, informar a respeito das mesmas, assim como de audiências públicas" e facilitar o acesso à justiça, terceiro e último direito procedimental ambiental.

4 Acuerdo regional sobre el acceso a la información, la participación pública y el acceso a la justicia en asuntos ambientales en América Latina y el Caribe.
} 
que os afetem, ${ }^{5}$ a participarem dos processos de decisões, ${ }^{6}$ e a possibilidade de recorrerem nos casos em que as decisões atinjam seus direitos. ${ }^{7}$

A abordagem ambiental foi introduzida mediante outros instrumentos internacionais, como a Carta Mundial para a Natureza de 1982 e a Declaração do Rio sobre Meio Ambiente e Desenvolvimento, como já mencionado. ${ }^{8}$

De acordo com o parágrafo 23 da Carta Mundial para a Natureza (1982):

Todas as pessoas, de acordo com a sua legislação nacional, deve têm (sic) a oportunidade de participar, individualmente ou com outros, na formulação de decisões que dizem diretamente respeito ao seu ambiente, e deve ter acesso a vias de recurso quando o ambiente sofreu danos ou degradação.

No entanto, a previsão mais importante sobre os direitos processuais ambientais está contida na Declaração do Rio no Princípio 10:

A melhor maneira de tratar as questões ambientais é assegurar a participação, no nível apropriado, de todos os cidadãos interessados. No nível nacional, cada indivíduo terá acesso adequado às informações relativas ao meio ambiente de que disponham as autoridades públicas, inclusive informações acerca de materiais e atividades perigosas em suas comunidades, bem como a oportunidade de participar dos processos decisórios. Os Estados irão facilitar e estimular a conscientização e a participação popular, colocando as informações à disposição de todos. Será proporcionado o acesso efetivo a mecanismos judiciais e administrativos, inclusive no que se refere à compensação e reparação de danos.

As normas participativas incorporadas no Princípio 10 parecem abrir áreas do domínio reservado do Estado. De fato, o reconhecimento dessas normas participativas, não obstante seja somente Soft Law, tem o potencial de adentrar aspectos fundamentais do Estado, incluindo o segredo de Estado, o procedimento legal e a Administração Pública.

A primeira implementação deste Princípio em um instrumento internacional vinculante foi a Convenção de Aarhus, sobre Acesso à Informação, Participação do Público no Processo de Tomada de Decisão e Acesso à Justiça em Matéria de Ambiente, assinada em Aarhus, na Dinamarca, em 25 de junho de 1998. Os propósitos da Convenção fazem parte do seu próprio título, ${ }^{9}$ e esses três aspectos conectados são considerados os seus três pilares. Tal abordagem foi denominada por Mazzuoli e

\footnotetext{
5 Art. 19: "Todo ser humano tem direito à liberdade de opinião e expressão; este direito inclui a liberdade de, sem interferência, ter opiniões e de procurar, receber e transmitir informações e idéias por quaisquer meios e independentemente de fronteiras."

6 Art. 21: "1. Todo ser humano tem o direito de fazer parte no governo de seu país diretamente ou por intermédio de representantes livremente escolhidos. 2. Todo ser humano tem igual direito de acesso ao serviço público do seu país. 3. A vontade do povo será a base da autoridade do governo; esta vontade será expressa em eleições periódicas e legítimas, por sufrágio universal, por voto secreto ou processo equivalente que assegure a liberdade de voto."

7 Art. 8: "Todo ser humano tem direito a receber dos tribunais nacionais competentes remédio efetivo para os atos que violem os direitos fundamentais que lhe sejam reconhecidos pela constituição ou pela lei."

8 A Agenda 21 também indicava que "Os indivíduos, os grupos e as organizações deveriam ter acesso a informações relevantes para os direitos ambientais, podendo ser baseados nos direitos políticos atuais, juntamente com o desenvolvimento do direito do indivíduo a tomar medidas para proteger o meio ambiente."

9 1) acesso à informação, 2) participação do público em processos de decisão e 3) acesso à justiça em matéria de ambiente.
} 
Ayala (2011) como o "tripé de Aarhus", que se baseia na vinculação entre os três direitos: "o processo de participação depende do acesso à informação, da mesma forma que o acesso à justiça garante o exercício dos direitos de participação e informação." (SAMPAIO, 2013).

O interesse especial dedicado à Convenção de Aarhus reside no fato de ser uma Convenção inovadora e um dos documentos internacionais que mais influenciaram a cultura jurídica europeia em matéria ambiental. ${ }^{10}$

Em uma dimensão formal, o Tratado confirma o papel da forma democrática para alcançar metas ambientais e fornece maneiras de se introduzirem mecanismos de democracia participativa e deliberativa nas diversas normatividades regionais e locais (PAROLA, 2013a).

Do ponto de vista espacial, não obstante seja um instrumento normativo elaborado e negociado no âmbito da Comissão Econômica das Nações Unidas para a Europa (CEE/ONU), os princípios que provê possuem conotação global, de maneira especial pelo fato de versarem sobre um tema de interesse de toda a sociedade mundial (AYALA; POMMER SENN, 2012). Também Bolssemann (2008) afirmou que, apesar da mencionada Convenção ser regional, "o seu significado é global e representa o Tratado mais elaborado sobre o Princípio 10 da Declaração do Rio."

De fato, a Convenção tem o potencial de espraiar transparência e democracia, e serve de exemplo para muitos países (LOOSE; PAROLA; POTO, 2015), como base para a adoção de normas em várias localidades, bem além dos limites da região europeia.

Além disso, a Convenção pode ser vista como um passo para a criação de novas formas de democracia e cidadania, pois assume que a construção de uma democracia ambiental ${ }^{11}$ somente poderá ser atingida com o envolvimento de todos os cidadãos, enfatizando o papel destes como indivíduos ou sob a forma de associações ou ONGs, reconhecendo-lhes direitos e deveres ambientais.

A Convenção representou e representa um avanço significativo em termos de democracia participativa e de direitos dos cidadãos. E constitui um importante instrumento que influencia e contribui para o aperfeiçoamento de uma cultura global de informação, participação e interferência da coletividade nos processos de decisão ambientalmente relevantes, e de transformação do arquétipo formal do Estado de Direito em uma substância material de democracia ambiental.

Embora tenha havido um forte impulso em muitos países europeus, e mesmo na União Europeia (PAROLA, 2013b, p. 10), e uma grande influência no plano internacional, nenhum dos países da América Latina e do Caribe é signatário da Convenção de Aarhus. Por isso, ela é pouco estudada ou divulgada no seu meio jurídico, apesar de ser considerada pela Organização das Nações Unidas (ONU) o instrumento mais avançado para a democracia ambiental.

\footnotetext{
10 Para uma explicação mais aprofundada, veja-se Parola (2013b).

11 "O modelo da Democracia Ambiental que, questionando a abordagem antropocêntrica de derivação principalmente eurocêntrica e propondo uma harmonia com a Natureza e instrumentos de participação, enquanto ideia ainda em construção na teoria e na prática, pode servir para aplicar respostas aos devastadores efeitos da crise ecológica. A construção de uma Democracia Ambiental pode, inclusive, contribuir com uma mudança de consciência dos indivíduos e a criação de uma nova forma de cidadania: uma cidadania ecológica;" (PAROLA, 2016, p. 23). Para maior aprofundamento neste tema, cf.: Parola (2013a) e Instituto de Ciências Jurídico-Políticas (2015).
} 
Porém, o "mais avançado" até o presente, porque no final de 2017 uma "nova Aarhus", com feições latino-americanas e caribenhas, ${ }^{12}$ deve surgir no panorama jurídico internacional e regional. Esse projeto regional de Acordo visa a estabelecer uma estratégia de caráter similar à Convenção de Aarhus, mas na região da América Latina e Caribe. Se esse Acordo também faz uso de instrumentos digitais, somente terá a metade do impacto que a Convenção de Aarhus teve nos países europeus no processo de implementação da democracia ambiental (PAROLA, 2013a, p. 1-60). A "nova Aarhus" será bastante falada pelo menos durante os próximos 10 anos.

\section{Futuro Acordo}

Seguindo o mencionado modelo jurídico criado pela Convenção de Aarhus, após quase 20 anos da sua vigência, é prevista a edição de uma "nova Aarhus", chamada de Acesso à Informação, Participação do Público no Processo de Tomada de Decisão e Acesso à Justiça em Assuntos Ambientais na América Latina e no Caribe, que está sendo elaborada desde 2012 pelos países da região da América Latina e Caribe. $\bigcirc$ futuro Acordo regional poderá implementar o compromisso dos países que o estão negociando de garantir aos cidadãos o acesso à informação, a participação no processo de tomada de decisões e o acesso à justiça no domínio do ambiente, reconhecendo que nesse âmbito a melhoria da efetividade dos três direitos aumentará a qualidade das decisões e contribuirá para a sensibilização dos cidadãos em relação às questões ambientais, permitindo-lhes manifestar as suas preocupações às autoridades estatais.

Como afirmado por Alicia Bárcena, Secretária Executiva da Comissão Econômica para a América Latina e o Caribe (CEPAL), e por Carlos de Miguel, Chefe da Unidade de Políticas para o Desenvolvimento Sustentável da Divisão de Desenvolvimento Sustentável e Assentamentos Humanos da CEPAL, o Acordo regional sobre o Princípio 10 enfatiza

[...] o círculo virtuoso entre direitos de acesso, proteção ambiental e direitos humanos, enfatizando que a participação informada e a transparência contribuem para melhorar as políticas ambientais e, portanto, a proteção ambiental, o que por sua vez permite o cumprimento de direitos substantivos como o direito de toda pessoa a um meio ambiente saudável, à vida e à saúde. [...] O momento para aprofundar a aplicação cabal do Princípio 10 não poderia ser mais oportuno. Os direitos de acesso consagrados neste princípio estão no coração da Agenda 2030 e permeiam e se manifestam em todos os objetivos de desenvolvimento sustentável. [...] Também pede que se garanta o acesso público à informação e se promovam leis e políticas não discriminatórias para o desenvolvimento sustentável. (BÁRCENA; MIGUEL, 2016).

O caminho desse Acordo começou durante a Conferência das Nações Unidas sobre Desenvolvimento Sustentável (Rio+20) (COMISSÃO ECONÔMICA PARA A AMÉRICA LATINA E O CARIBE, 2012), realizada no Rio de Janeiro em junho de 2012, na qual um grupo de países da

\footnotetext{
$\overline{12} \mathrm{O}$ artigo seguirá a terminologia do futuro Acordo, que se refere nominalmente à América Latina e ao Caribe.
} 
América Latina e do Caribe assinou a Declaração sobre a aplicação do Princípio 10 da Declaração do Rio. Por meio dessa Declaração, os países signatários se comprometeram a avançar, com o apoio da CEPAL como secretaria técnica, na consecução de um acordo regional que facilite a implementação dos direitos de acesso à informação, à participação e à justiça em matéria ambiental (COMISSÃO ECONÔMICA PARA A AMÉRICA LATINA E O CARIBE, 2017b).

O processo regional está aberto a todos os países da América Latina e do Caribe, e, até o presente momento, a Declaração foi assinada por 33 países que integram o Comitê de Negociação. ${ }^{13}$

Entre 2012 e $2014,{ }^{14}$ houve quatro reuniões de pontos focais designados pelos governos dos países signatários. Nessas reuniões, os países adotaram os seguintes documentos de base: Roteiro, Plano de ação e Visão de Lima; Linhas de ação prioritárias em matéria de fortalecimento de capacidades e cooperação; Conteúdos de São José; e Decisão de Santiago. Por meio deste último documento, em novembro de 2014, os países signatários iniciaram a etapa de negociação do instrumento regional sobre acesso à informação, à participação e à justiça em matéria ambiental. Para tanto, criaram um Comitê de Negociação composto por representantes dos países signatários, com vistas à conclusão dos trabalhos, no mais tardar, em dezembro de 2017. As reuniões do Comitê contam com significativa participação de diversas Organizações Não Governamentais, ${ }^{15}$ de acordo com as disposições e modalidades dispostas no Plano de Ação.

O Comitê de Negociação realizou seis encontros: em maio de 2015 (COMISSÃO ECONÔMICA PARA A AMÉRICA LATINA E O CARIBE, 2015) em Santiago, em outubro de 2015, na Cidade do Panamá, em abril de 2016 em Montevidéu, em agosto de 2016 em Santo Domingo, em novembro de 2016 em Santiago e em março de 2017 em Brasília, DF, avançando neste último a negociação do Acordo Regional a partir do texto que reúne as propostas de texto de todos os países. ${ }^{16}$

Para a redação deste artigo, utilizamos o texto oficial em espanhol do Acordo, de 26 de dezembro de $2016,{ }^{17}$ preparado quando da sexta reunião e que, apesar de não ser o definitivo, pode esclarecer muitos pontos sobre as novidades introduzidas no rumo de uma efetivação dos direitos de acesso, cujo exercício pode ser facilitado com a internet como meio para os cidadãos acederem rapidamente a informações e notícias sobre o meio ambiente (COMISSÃO ECONÔMICA PARA A AMÉRICA LATINA E O CARIBE, 2016).

\footnotetext{
$\overline{13}$ Antigua y Barbuda; Argentina (la); Bahamas (las); Barbados; Belice; Bolivia (Estado Plurinacional de) (el); Brasil (el); Chile; Colombia; Costa Rica; Cuba; Dominica; Ecuador (el); El Salvador; Granada; Guatemala; Guyana; Haití; Honduras; Jamaica; México; Nicaragua; Panamá; Paraguay (el); Perú (el); República Dominicana (la); Saint Kitts y Nevis; San Vicente y las Granadinas; Santa Lucía; Suriname; Trinidad y Tabago; Uruguay (el); Venezuela (República Bolivariana de) (la).

14 Também foram criados, nesse período, dois grupos de trabalho com o objetivo de avançar nas discussões: o Grupo de Trabalho I, sobre fortalecimento de capacidades e cooperação, e o Grupo de Trabalho II, sobre direitos de acesso e instrumento regional. Esses grupos reuniram-se em 14 ocasiões e concluíram seus respectivos mandatos em novembro de 2014.

15 Entre outras, participaram as seguintes ONGs: Article 19 (ONG brasileira: <www.artigo19.org>); Rede Gaia (ONG brasileira: <www.redegaia.com.br>); e Centro Mexicano de Derecho Ambiental (Cemda) (ONG mexicana: <www.cemda.org. $\mathrm{mx}>$ ).

16 O sétimo encontro foi realizado em agosto de 2017 em Buenos Aires, mas as partes não finalizaram a negociação e ainda não foi produzida a redação final do texto.

17 Não existe uma versão oficial em português, somente em espanhol e inglês.
} 


\section{Os direitos ambientais na Aarhus e na "Nova Aarhus"}

A Convenção de Aarhus influenciou muito o futuro Acordo, mas, como será demonstrado adiante, há muitas novidades de cunho latino-americano e caribenho e a respeito dos instrumentos digitais, ferramentas que, na época da aprovação da Convenção de Aarhus, ainda estavam longe de imaginação. Relativamente à arquitetura e ao conteúdo do Acordo, de fato, há uma forte aproximação e uma compatibilidade com o modelo definido pela Convenção de Aarhus. A importância da Convenção pode ser verificada na menção que lhe foi feita nos objetivos do Acordo no documento preliminar redigido em Santiago, ${ }^{18}$ posteriormente repetido no Preâmbulo da última versão do acordo de dezembro de $2016 .^{19}$

O primeiro ponto que deve ser evidenciado é o da correspondência estrutural das duas Convenções: há uma simetria entre os seus respectivos artigos relativamente ao conteúdo e, talvez, também aos números. Por exemplo, o artigo $1^{\circ}$ é dedicado aos "Objetivos" (na Aarhus) e ao "Objetivo" (no Acordo); o artigo $2^{\circ}$ trata das "Definições" (na Aarhus e no Acordo); e o artigo $3^{\circ}$ veicula as "Disposições gerais" (Aarhus) e os Princípios (no Acordo).

Relativamente ao artigo $1^{\circ}$, em ambos os documentos há o reconhecimento do meio ambiente sadio; a Convenção de Aarhus, no seu artigo $1^{\circ}$, faz a conjunção entre o direito ao meio ambiente sadio ${ }^{20}$ e os direitos processuais:

Com o objetivo de contribuir para a proteção do direito de todos os indivíduos, das gerações presentes e futuras, a viver num ambiente propício à sua saúde e bem-estar, cada Parte garantirá a concessão dos direitos de acesso à informação, à participação do público no processo de tomada de decisões e à justiça no domínio do ambiente, em conformidade com o disposto na presente Convenção.

O artigo $1^{\circ}$ do documento preliminar, intitulado Objetivo, estabelece que o objetivo principal do Acordo é a realização do direito de viver em um ambiente saudável e sustentável, mediante a efetiva aplicação na América Latina e no Caribe dos direitos de acesso consagrados no Princípio 10 da Declaração do Rio:

\footnotetext{
18 O documento original foi elaborado pela Secretaria da CEPAL e apresentado por ocasião da I Reunião do Comitê de Negociação sobre a matéria (COMISSÃO ECONÔMICA PARA A AMÉRICA LATINA E O CARIBE, 2015). Este último afirma, similarmente à Convenção de Aarhus, que toda pessoa tem o direito a um meio ambiente saudável e em harmonia com a natureza, o que é indispensável para a dignidade e o desenvolvimento integral do ser humano e para a conquista do desenvolvimento sustentável, a erradicação da pobreza, a igualdade e a preservação e gestão adequada do meio ambiente em benefício das gerações presentes e futuras.

19 Preâmbulo, parágrafo 6 bis.

20 Este direito é considerado um direito fundamental de "terceira geração", parte dos chamados direitos de solidariedade ou fraternidade. Esses direitos são considerados direitos da coletividade, possuindo um caráter difuso e constituindo um direito-dever de todos. A ideia do meio ambiente como um direito humano foi pela primeira vez consagrada no Princípio $1^{\circ}$ da Declaração de Estocolmo de 1972 da Conferência das Nações Unidas sobre o Meio Ambiente Humano (ALMEIDA, 2012, p. 83-102).
} 
O objetivo deste Acordo é assegurar a aplicação plena e efetiva [Colômbia: plena e efetiva progressiva] dos direitos de acesso consagrados no Princípio 10 da Declaração do Rio de 1992, sobre a base da cooperação e a criação de capacidades, [San Vicente y las Granadinas: para garantir o respeito e a implementação plena desses direitos] com a finalidade de proteger o direito das gerações presentes e futuras a viver em um meio ambiente são. ${ }^{21}$

Nesse sentido, fica evidente e a semelhança entre a "Nova Aarhus" e a Convenção de Aarhus.

Com respeito, depois, ao primeiro pilar da Convenção, o acesso à informação é disciplinado pelo artigo $4^{\circ}$ (Acesso à informação em matéria de ambiente) e pelo artigo $5^{\circ}$ (Recolha e difusão de informação em matéria de ambiente). No Acordo esse direito está previsto também em dois artigos, que parecem ter conteúdo muito similar já nos seus títulos: o artigo $6^{\circ}$ (Acceso a la información ambiental) e o artigo $7^{\circ}$ (Generación y divulgación de información ambiental).

O segundo pilar da Convenção de Aarhus, relativo à participação, corresponde aos artigos $6^{\circ}$ (Participação do público em decisões sobre atividades específicas), $7^{\circ}$ (Participação do público relativamente a planos, programas e políticas em matéria de ambiente) e $8^{\circ}$ (Participação do público na preparação de regulamentos e/ou instrumentos normativos legalmente vinculativos aplicáveis na generalidade), que no Acordo está concentrado em um único artigo: o $8^{\circ}$ (Participación del público en la toma de decisiones ambientales).

Enfim, em relação ao acesso à justiça, que corresponde ao terceiro pilar da Convenção, enunciado no artigo 9, que no Acordo também aparece no seu artigo $9^{\circ}$ (Acceso a la justicia).

Adiante aprofundaremos todos esses direitos em série.

\subsection{0 direito de acesso à informação na Convenção e no Futuro Acordo}

Como primeiro pilar, a Convenção destaca o acesso à informação ${ }^{22}$ como base dos outros direitos, pois é preciso que a sociedade esteja adequadamente informada para que possa fazer escolhas adequadas e conscientes: "A informação serve para o processo de educação de cada pessoa e da comunidade, mas a informação visa também dar a chance à pessoa informada de tomar posição ou pronunciar-se sobre a matéria informada." (MACHADO, 2013, p. 123).

$O$ direito à informação pode indicar, de forma restrita, a liberdade de se procurar informação ou, amplamente, o direito de acesso à informação, ou mesmo o direito de a obter. O Estado tem

\footnotetext{
21 No original: "El objetivo de este Acuerdo es asegurar la aplicación plena y efectiva [Colombia: plena y efectiva progresiva] de los derechos de acceso consagrados en el Principio 10 de la Declaración de Río de 1992, sobre la base de la cooperación y la creación de capacidades, [San Vicente y las Granadinas: para garantizar el respeto y la implementación plena de esos derechos] con el fin de proteger el derecho de las generaciones presentes y futuras a vivir en un medio ambiente sano."

22 O artigo 19 da Declaração Universal dos Direitos Humanos, o artigo 19 do Pacto Internacional sobre Direitos Civis e Políticos, o artigo 13 da Convenção Interamericana sobre Direitos Humanos, o artigo $9^{\circ}$ da Carta Africana sobre Direitos Humanos e dos Povos e o artigo 10 da Convenção Europeia sobre Direitos Humanos reconhecem o acesso às informações públicas como direito humano fundamental.
} 
o dever de abster-se de interferir com a ação pública para obter informações de determinadas autoridades estatais ou de entidades privadas. Um outro dever do Estado é divulgar todas as informações relevantes sobre planos e projetos públicos e privados que possam ter impacto no meio ambiente.

Para salientar essa importância, foi sugerido que o acesso à informação governamental deve ser considerado um direito humano fundamental, pois o conhecimento das atividades de seus líderes é visto como crucial para a manutenção de outros direitos humanos. Como foi sublinhado também por Holder e Lee (2007, p. 100): "O acesso à informação é um elemento crucial de uma sociedade democrática, uma condição prévia para os direitos básicos de voto ou de liberdade de expressão e, certamente, de qualquer forma de participação na tomada de decisões." ${ }^{23}$

A ideia subjacente é que os cidadãos têm o direito de conhecer os métodos de exercício do poder das autoridades em seu nome e, portanto, o acesso à informação pode contribuir para um melhor envolvimento dos cidadãos nas tarefas de seus governos.

Além disso, o acesso à informação também oportuniza tornar o processo de decisão ambiental mais democrático e eficiente. Por essa razão, o acesso à informação é um requisito essencial para o exercício dos direitos de participação.

Os artigos na Convenção de Aarhus relacionados à informação são o $4^{\circ}$ (acesso passivo) e o $5^{\circ}$ (acesso ativo) e têm como objetivo romper com o segredo que por muito tempo envolveu as autoridades públicas, impedindo que as informações fornecidas fossem de fato transparentes (STEC; CASEY-LEFKOWITZ, 2000, p. 18).

O direito em questão é dividido em duas partes: a primeira diz respeito à informação "passiva", que é o direito do público de procurar e obter informações junto às autoridades públicas e a obrigação destas de proverem as informações requisitadas.

O segundo artigo, chamado de acesso "ativo", envolve o direito do público de receber informações e a obrigação das autoridades de coletar e disseminar essas informações de interesse geral, sem a necessidade de esta ser demandada pelo público (SAMPAIO, 2013).

O novo Acordo segue a divisão introduzida pela Convenção entre o acesso "passivo" disciplinado pelo artigo $6^{\circ}$ (Acceso a la información ambiental) e o acesso "ativo" enunciado no artigo $7^{\circ}$ (Generación y divulgación de información ambiental). Os dois artigos atualmente estão distantes de ser definitivos porque, como resultam da última versão do Acordo, ainda há muitos pontos sobre os quais as partes ainda não concordam. Uma novidade importante que aparece no parágrafo $3^{\circ}$ do artigo $6^{\circ}$ é a particular atenção dada aos grupos de pessoas mais vulneráveis e aos índios:

As Partes facilitarão o acesso à informação das pessoas e/ou grupos em situação de vulnerabilidade, estabelecendo procedimentos de atenção desde a formulação de solicitações até a entrega da informação, considerando suas condições e especificidades, com a finalidade de fomentar o acesso e a participação em igualdade de condições. (Convenção)

23 "Access to information is a crucial element of a democratic society, a precondition to basic rights to vote or free speech, and certainly of any form of participation in decision making." 
Cada Parte garantirá que ditas pessoas e/ou grupos em situação de vulnerabilidade, incluindo os membros de povos indígenas e grupos étnicos, recebam assistência para formular suas petições e obter resposta. ${ }^{24}$

Assim, a inclusão dos mencionados sujeitos traz no Acordo uma marca tipicamente latino-americana, pois toca em aspectos ligados principalmente à realidade e à história do continente.

\subsection{0 direito à participação na Convenção e no Acordo}

O segundo pilar da Convenção, a participação pública no processo de decisão, necessita dos outros dois pilares para sua eficácia e efetividade. $O$ acesso à informação também propicia a oportunidade de tornar o processo de decisão ambiental um processo mais democrático e eficiente. Por essa razão, o acesso à informação é um requisito essencial para o exercício dos direitos de participação. O pilar da informação garante que o público participe de forma mais consciente e informada, e o pilar de acesso à justiça garante que a participação aconteça de fato.

O direito à participação na Convenção de Aarhus figura nos artigos $6^{\circ}, 7^{\circ}$ e $8^{\circ}$ : o primeiro dispõe sobre quando a população é afetada por um empreendimento específico. $O$ segundo diz respeito à participação do público na elaboração de planos, programas e políticas relativos ao ambiente. O terceiro se refere à participação do público na elaboração de normas legais. Este último é, portanto, o direito do público de avaliar, discutir ou influenciar as decisões sobre política ambiental ou os projetos individuais que afetem a sua comunidade. Como foi notado por Sampaio (2013, p. 14253):

Esse detalhamento da participação mostra a preocupação em garantir a promoção da democracia ambiental, pois a política de proteção ambiental necessita da participação do cidadão comum, na mesma medida em que necessita da participação de cientistas e especialistas. O que a Convenção objetiva é que o público, através de grupos organizados, exercite sua influência na fase legislativa da elaboração de um plano ou lei ambiental e não, apenas, na fase de implementação.

Com respeito ao direito à participação no Acordo, há um único artigo, o $8^{\circ}$ (Participación del público en la toma de decisiones ambientales), que junta em parte o conteúdo dos artigos $6^{\circ}$ e $7^{\circ}$ da Convenção. A possibilidade do público de participar na elaboração de normas legais, prevista no artigo $8^{\circ}$ da Convenção, não foi incluída até o presente momento no Acordo; o único vago passo nessa direção é previsto no parágrafo $n$. 4, que versa sobre a possibilidade de participar quando a autoridade pública reconsidera ou atualiza projetos, atividades, políticas, planos, regras, regulamentos, programas e estratégias: "Cada Parte velará por que quando uma autoridade pública reexamine

\footnotetext{
24 No original: "Las Partes facilitarán el acceso a la información de las personas y/o grupos en situación de vulnerabilidad, estableciendo procedimientos de atención desde la formulación de solicitudes hasta la entrega de la información, considerando sus condiciones y especificidades, con la finalidad de fomentar el acceso y la participación en igualdad de condiciones. (Convenido).

Cada Parte garantizará que dichas personas y/o grupos en situación de vulnerabilidad, incluyendo a los miembros de pueblos indígenas y grupos étnicos, reciban asistencia para formular sus peticiones y obtener respuesta."
} 
ou atualize projetos, atividades, políticas, planos, normas, regulamentos, programas e estratégias suscetíveis de gerar impactos ambientais, se respeitem as disposições contidas no presente artigo." ${ }^{25}$

Também aqui, como mencionado em relação ao direito ao acesso à informação, há uma pegada latino-americana e caribenha, obviamente assente em Aarhus, quando o Acordo adiciona o dever de facilitar a participação das pessoas integrantes dos grupos mais desfavorecidos e dos índios:

13. As Partes apoiarão o estabelecimento de [Chile: apoiarão o estabelecimento de que contarão com] espaços formais e permanentes [Antigua y Barbuda: formais e permanentes aprovados] de consulta sobre assuntos ambientais nos quais participem representantes de distintos grupos e setores. As Partes promoverão la valoração do conhecimento local, o diálogo e a interação das diferentes visões e saberes. [Chile: a interação das diferentes visões e saberes e a paridade de gênero.]

14. As Partes realizarão esforços para identificar e apoiar [pessoas e grupos em situação de vulnerabilidade] de modo a envolvê-los de maneira ativa, oportuna e efetiva. Para estes efeitos serão considerados os melhores [Argentina: melhor adequados] meios e formatos, apoiando sua participação e assegurando o respeito a suas próprias características culturais. ${ }^{26}$ (grifo nosso).

No parágrafo $13^{\circ}$ consta uma das mais importantes novidades: o Acordo segue, ainda que timidamente, o caminho traçado pelo novo constitucionalismo latino-americano (ÁVILA SANTAMARÍA, 2011; BRAGATO; FERNANDES, 2015, p. 15; OLIVEIRA FILHO, 2014, p. 31), quando reconhece a importância do valor do conhecimento local e da promoção do diálogo e a interação de diferentes visões e conhecimentos.

\subsection{0 direito de acesso à justiça na Convenção e no Acordo}

Por fim, a Convenção de Aarhus, no seu artigo 9 ${ }^{\circ}$, refere-se ao acesso à justiça como seu terceiro pilar. Recomenda que os países signatários incorporem nas suas legislações nacionais mecanismos que assegurem a viabilização dos dois pilares anteriores. Além disso, a oportunidade de acionarem a justiça nas causas ambientais proporciona importante reforço para o poder dos cidadãos de requererem informação ambiental e de participarem no processo de decisão na implementação e na fiscalização pela utilização do poder da lei. Esse acesso é entendido como a possibilidade de os cidadãos solicitarem aos tribunais ou outros organismos imparciais independentes a revisão de atos ou decisões que importem em violações potenciais aos itens preconizados pela Convenção: acesso à informação e à participação pública.

\footnotetext{
25 No original: "Cada Parte velará por que cuando una autoridad pública reexamine o actualice proyectos, actividades, políticas, planes, normas, reglamentos, programas y estrategias susceptibles de generar impactos ambientales, se respeten las disposiciones contenidas en el presente artículo."

26 No original: "13. Las Partes alentarán el establecimiento de [Chile: alentarán el establecimiento de contarán con] espacios formales y permanentes [Antigua y Barbuda: formales y permanentes aprobados] de consulta sobre asuntos ambientales en los que participen representantes de distintos grupos y sectores. Las Partes promoverán la valoración del conocimiento local, el diálogo y la interacción de las diferentes visiones y saberes. [Chile: la interacción de las diferentes visiones y saberes y la paridad de género.] 14. Las Partes realizarán esfuerzos para identificar y apoyar a [personas y grupos en situación de vulnerabilidad] de modo de involucrarlos de manera activa, oportuna y efectiva. Para estos efectos se considerarán los mejores [Argentina: mejores adecuados] medios y formatos, apoyando su participación y asegurando el respeto a sus propias características culturales." (grifo nosso).
} 
O artigo $9^{\circ}$ da "nova Aarhus" também é dedicado ao Acceso a la justicia, e no primeiro parágrafo reconhece, de maneira geral, que cada Estado deverá garantir o direito de acesso à justiça em matéria ambiental, em um prazo razoável, por meios administrativos e/ou judiciais. No seu segundo parágrafo, o artigo $9^{\circ}$ praticamente reproduz o conteúdo da Convenção de Aarhus, fazendo referência à possibilidade de cada pessoa contestar a legalidade de:

a) qualquer decisão, ação ou omissão relacionadas ao acesso à informação ambiental;

b) qualquer decisão, ação ou omissão, em substância e procedimento relacionados à participação do público na tomada de decisões sobre questões ambientais;

c) qualquer decisão, ação ou omissão, de qualquer indivíduo, entidade pública ou entidade privada que possa afetar o meio ambiente ou infringir os seus méritos ou normas legais processuais do Estado relacionadas ao meio ambiente.

Em relação a esse artigo, os países latino-americanos e caribenhos ainda estão longe de um acordo, e muitos outros parágrafos e propostas de modificações a seu respeito persistem em discussão entre as Partes. Na reunião de agosto em Buenos Aires poderão ser finalizadas.

\section{0 futuro Acordo e os instrumentos digitais}

O futuro Acordo faz muitas referências aos instrumentos digitais.

Primeiro, deve ser citado o avanço apresentado durante a sexta reunião em março de 2017, na qual foi lançado um novo e fundamental instrumento on-line que amplia o acesso às informações, denominado Observatório do Princípio 10 na América Latina e no Caribe (COMISSÃO ECONÔMICA PARA A AMÉRICA LATINA E O CARIBE, 2017a). Essa ferramenta acompanhará leis, políticas, tratados e jurisprudências que garantam os direitos das pessoas à informação, à participação e à justiça em assuntos ambientais.

Esse Observatório digital é uma iniciativa da CEPAL para contribuir para uma melhor compreensão, difusão e aplicação dos direitos de acesso. Nas mesmas referências pendentes para os direitos de acesso estabelecidos nos tratados internacionais de que os países da região são parte estão incluídas disposições e outras informações de interesse sobre esses direitos contidos nas constituições, leis, regulamentos, planos, estratégias oferecidas e políticas nacionais dos 33 países da América Latina e do Caribe. Da mesma forma, está incluída tal jurisprudência sobre direitos de acesso em questão (COMISSÃO ECONÔMICA PARA A AMÉRICA LATINA E O CARIBE, 2017a).

Como um centro de informação on-line, o Observatório tem como objetivo promover sinergias e melhorar a coordenação na capacitação em direitos de acesso em matérias ambientais em nível regional. Ele também pretende ser uma contribuição para as negociações para o desenvol- 
vimento do futuro acordo regional (COMISSÃO ECONÔMICA PARA A AMÉRICA LATINA E O CARIBE, 2017a).

Diferentemente da Convenção de Aarhus, na qual não se considerava ainda a revolução digital que ocorria na época da sua aprovação, visto que essa mudança tinha apenas começado (1998), o futuro Acordo prevê artigos que reconhecem a importância dos instrumentos digitais para a eficácia e a efetividade dos direitos de acessos.

Um exemplo é o do artigo $2^{\circ}$ (Definiciones) (COMISSÃO ECONÔMICA PARA A AMÉRICA LATINA E O CARIBE, 2016), no qual se clarifica o que significa, para os efeitos do presente Acordo, o termo informação ambiental. Com essa expressão se entende:

[...] aquela informação escrita, visual, sonora, eletrônica ou registrada de qualquer outra forma, relacionada com o estado do meio ambiente e os recursos naturais, [...] incluída a informação sobre possíveis impactos adversos vinculados ao meio ambiente $[\ldots]$ e a saúde humana. ${ }^{27}$ (grifo nosso).

O artigo $5^{\circ}$, relativo às Obligaciones generales, faz referência, no seu parágrafo 13 , às novas tecnologias de informação e comunicação:

Para garantir os direitos de acesso, as Partes apoiarão [...] o uso das novas tecnologias de informação e das comunicações, [...] o governo eletrônico, as redes e meios sociais e telemáticos, entre outros, [...] em todos os idiomas [...], incluídos os utilizados pelos povos indígenas. ${ }^{28}$ (grifo nosso).

Além disso, o parágrafo 16 do artigo $6^{\circ}$, quando disciplina o acesso à informação passiva, menciona a proibição de custo: La información enviada de manera electrónica no podrá tener ningún costo.

Também no artigo que trata do acesso à informação ativa, o artigo $7^{\circ}$ (Generación y divulgación de información ambiental), no parágrafo $3^{\circ}$, declara que:

'Cada Parte deverá garantir que os sistemas de informação ambiental estejam devidamente organizados, sejam acessíveis para todas as pessoas e estejam disponíveis de forma progressiva por meios informáticos e geograficamente referenciados nos casos que correspondam. [Convênio]'. O Parágrafo 7. 'Os informes deverão ser redigidos de modo que sejam de fácil compreensão e possam estar acessíveis ao público em diferentes formatos e ser difundidos através de meios apropriados considerando suas realidades culturais'. ${ }^{29}$ (grifo nosso).

\footnotetext{
27 No original: "[...] aquella información escrita, visual, sonora, electrónica o registrada de cualquier otra forma, relacionada con el estado del medio ambiente y los recursos naturales, [...] incluida la información sobre posibles impactos adversos vinculados con el medio ambiente [...] y la salud humana."

28 No original: "Para garantizar los derechos de acceso, las Partes alentarán [...] el uso de las nuevas tecnologías de la información y las comunicaciones, [...] el gobierno electrónico, las redes y medios sociales y telemáticos, entre otros, [...] en todos los idiomas [...], incluidos los utilizados por los pueblos indígenas."

${ }_{29}$ No original: "Cada Parte deberá garantizar que los sistemas de información ambiental se encuentren debidamente organizados, sean accesibles para todas las personas y estén disponibles de forma progresiva por medios informáticos y georreferenciados en los casos que correspondan. [Convenido] [. O Parágrafo 7. 'Los informes deberán ser redactados de manera que sean de fácil comprensión y podrán estar accesibles al público en diferentes formatos y ser difundidos a través de medios apropiados considerando sus realidades culturales'."
} 
Enfim, o artigo 9, que regula o Acceso a la justicia, no seu parágrafo $5^{\circ}$, alínea "c", afirma que "Para facilitar el acceso a la justicia en asuntos ambientales, las Partes establecerán: [...] c) nuevos mecanismos, incluidos [...] virtuales, electrónicos y telefónicos."

\section{Considerações finais}

Neste artigo procuramos apresentar e debater os direitos de acesso em matéria ambiental como direitos humanos e sua efetividade, confrontando as principais semelhanças e diferenças entre a Convenção de Aarhus e a "Nova Aarhus", o futuro Acordo Regional sobre o Princípio 10, e evidenciar como os instrumentos digitais entram fortemente no futuro Acordo. Considerando o andamento das negociações entre os países latino-americanos e caribenhos, trazemos as seguintes conclusões parciais. A proposta é a de que, quando concluído, o futuro Acordo Regional sirva aos países signatários como paradigma e referencial ético na construção de uma democracia ambiental na América Latina e no Caribe (e por que não uma democracia ambiental digitalé).

Com isso, a revolução digital e os instrumentos digitais trazem maior poder às mãos dos cidadãos para se fazerem ouvir, se considerada a situação anterior dos meios de comunicação. Se anos atrás o poder de acesso de um cidadão tinha pouco alcance, atualmente a expansão do acesso digital confere um poder muito maior e "a tecnologia é a mola propulsora desse novo poder popular." (TAVARES, 2015).

Portanto, a utilização da internet como plataforma de informação pode atingir uma escala quase ilimitada de pessoas ao redor do mundo e no Brasil, impulsionando uma democracia digital do acesso à informação ambiental.

Assim, os instrumentos digitais e a tecnologia podem ajudar na realização de uma democracia ambiental, entendida como um amplo poder de acesso à informação, à participação e à justiça em matéria ambiental. Todavia, essa possibilidade ainda não foi significativamente incorporada na realidade brasileira. Devemos lembrar que existe no Brasil o dito Apartheid digital, no qual há $\square$ dois tipos de cidadãos, aqueles que podem acessar instantaneamente [...], e aqueles que estão privados da velocidade de comunicação." (SILVEIRA, 2001, p. 48-49).

Por isso, é necessário avançar no caminho para "dar mais espaço à cidadania empoderada"(BÁRCENA: 2015) por meio também do futuro Acordo sobre o Princípio 10, que, nesse sentido, possui também um valor social. Por essa última razão, quando o Brasil assinar o Acordo terá a obrigação de facilitar a implementação do acesso à informação, em particular sobre o meio ambiente, viabilizando o acesso ao meio ambiente digital a um número maior de indivíduos, de modo a reduzir as desigualdades sociais (um dos objetivos fundamentais da República, previsto no artigo $3^{\circ}$, III, da $\mathrm{CF} / 88) \cdot{ }^{30}$

${ }_{30}$ Art. $3^{\circ}$ - Constituem objetivos fundamentais da República Federativa do Brasil: $[\ldots]$

EJJL 
Embora seja importante não esquecer que uma democracia ambiental digital não é, com certeza, a panaceia de todos os males, os direitos de acessos, graças ao meio digital, podem ajudar a proteger os cidadãos em geral e aqueles em situações de maior fragilidade em particular.

Como resultados parciais da pesquisa, considerando a previsão de aprovação do futuro Acordo Regional para o final do ano 2017, resta identificado um indicativo claro da formulação de um paradigma normativo e um referencial ético na construção de uma democracia ambiental na América Latina e no Caribe, bem como uma democracia ambiental digital, que instituem novos direitos humanos e trazem os respectivos mecanismos de efetividade.

\section{Referências}

ALMEIDA, Guilherme de. Acesso à justiça, direitos humanos e novas esferas da justiça. Contemporânea - Revista de Sociologia da UFSCar, São Carlos, v. 2, n. 1, p. 83-102, jan./jun. 2012.

ÁVILA SANTAMARÍA, Ramiro. El neoconstitucionalismo transformador: el Estado y el derecho en la Constitución de 2008. Quito: Abya-Yala: Universidad Andina Simón Bolívar; Fundación Rosa Luxemburg, 2011.

AYALA, Patryck de Araujo; POMMER SENN, Adriana. Cooperação internacional em Matéria Ambiental: Elementos do Direito Brasileiro e do Direito Internacional do Meio Ambiente. Rev. direito GV, v. 8, n. 1, São Paulo, jan./jun. 2012.

BÁRCENA, Alicia. A Revolução Digital para o Desenvolvimento Sustentável e Inclusivo. CEPAL, abr. 2015. Disponível em: <http://www.cepal.org/pt-br/articulos/2015-revolucao-digital-para-o-desenvolvimento-sustentavel-e-inclusivo>. Acesso em 1 de abril de 2017.

BÁRCENA, Alicia; MIGUEL, Carlos de. Mais cidadania para o desenvolvimento sustentável. CEPAL, n. 88, jun. 2016. Disponível em: <http://www.cepal.org/pt-br/articulos/2016-mais-cidadania-o-desenvolvimento-sustentavel>. Acesso em: 01 abr. 2017.

BOSSELMANN, Kraus. The Principle of Sustainability. Aldershot: Ashgate Publishing Company, 2008.

BRAGATO, Frizzo, Fernanda; FERNANDES, Macedo, Karina. Da colonialidade do poder à descolonialidade como horizonte de afirmação dos direitos humanos no âmbito do constitucionalismo latino-americano. Revista Culturas Jurídicas, Niterói, v. 2, n. 4, 2015. Disponível em: <http://www. culturasjuridicas.uff.br/index.php/rcj/article/view/157/57>. Acesso em: 24 abr. 2017.

BRASIL. Constituição. República Federativa do Brasil de 1988. Brasília, DF: Senado Federal, 1988.

COMISSÃO ECONÓMICA DAS NAÇÕES UNIDAS PARA A EUROPA. Convenção sobre acesso à informação, participação do público no processo de tomada de decisão e acesso à Justiça em matéria de Ambiente (Convenção de Århus). Dinamarca, 25 jun. 1998. Disponível em: <https://www.unece.org/ fileadmin/DAM/env/pp/EU\%20texts/conventioninportogese.pdf>. Acesso em: 24 abr. 2017.

III - erradicar a pobreza e a marginalização e reduzir as desigualdades sociais e regionais; 
COMISSÃO ECONÔMICA PARA A AMÉRICA LATINA E O CARIBE. Documento Preliminar. Instrumento regional sobre acesso à informação, participação pública e acesso à justiça em assuntos ambientais na América Latina e no Caribe. Santiago, 05-07 maio 2015. Disponível em: < http:// www.cepal.org/sites/default/files/pages/files/doc_preliminar_p10_rubens_born_fgeb_fboms.pdf>. Acesso em: 01 abr. 2017.

COMISSÃO ECONÔMICA PARA A AMÉRICA LATINA E O CARIBE. Nota verbal de 27 de junho de 2012 dirigida ao Secretário-Geral da Conferência das Nações Unidas sobre Desenvolvimento Sustentável e la Missão Permanente do Chile junto às Nações Unidas. 2012. Disponível em: <http://www.cepal. org/sites/default/files/pages/files/declaracion_principio_10_portugues_editorial.pdf $>$. Acesso em: 01 abr. 2017.

COMISSÃO ECONÔMICA PARA A AMÉRICA LATINA E O CARIBE. Observatorio del Principio 10 en América Latina y el Caribe. Disponível em: <http://observatoriop10.cepal.org/es>. Acesso em: 24 abr. 2017a.

COMISSÃO ECONÔMICA PARA A AMÉRICA LATINA E O CARIBE. Reunião do Comitê de Negociação - Princípio 10 na América Latina e no Caribe. Disponível em: <http://www.cepal.org/rio20/ principio10>. Acesso em: 01 abr. 2017 b.

COMISSÃO ECONÔMICA PARA A AMÉRICA LATINA E O CARIBE. Texto compilado por la mesa directiva que incluye las propuestas de texto de los países relativas al preámbulo y los artículos 1 a 10 del documento preliminar del acuerdo regional sobre el acceso a la información, la participación pública y el acceso a la justicia en asuntos ambientales en América Latina y el Caribe - Quinta Versión. 26 dez. 2016. Disponível em: <http://negociacionp10.cepal.org/6/es/documentos/sexta-version-texto-compilado-la-mesa-directiva-que-incluye-propuestas-texto-paises >. Acesso em: 01 abr. 2017.

FIORILlO, Celso Antonio Pacheco; WALDMAN, Ricardo Libel. Fundamentos Constitucionais do Meio@mbiente Digit@1 no Direito Brasileiro em Face da Sociedade da Informação e sua Relação com os Direitos Humanos Constitucionais. In: SOUZA, José Fernando Vidal de Souza; CAMPELLO, Livia Gaigher Bosio; RIZZO, Roxana Lilian Corbran. Direito Ambiental e Socioambientalismo $I V$ - Anais do V Encontro Iinternacional Do Conpedi (Montevidéu - Uruguai. Florianópolis: Ed. CONPEDI, 2016. p. 139.

FIORILLO, Celso Antonio Pacheco, MARTINEZ, Regina Célia. Os 20 anos da internet no Brasil, seus reflexos no Meio ambiente Digital e sua tutela jurídica na sociedade da informação. 2015. Disponível em: $<$ http://portal.fmu.br/mestrado/direito/arquivos/publicacao_livro20Anos.pdf > . Acesso em: 24 abr. 2017.

HOLDER, Jane; LEE, Maria. Environmental Protection, Law and Policy. Cambridge: Aspen Publishers, 2007.

INSTITUTO DE CIÊNCIAS JURÍDICO-POLÍTICAS. A trilogia de Aarhus: os direitos à informação, à participação e à justiça ambiental. Lisboa: Faculdade de Direito Universidade de Lisboa, 2015.

KRAMER, Ludwig. Access to information in an Open European Society - Directive 2003/4. EC Environemental Law. Yearbook European Environmental Law, 2004.

LOOSE, Eva; PAROLA, Giulia; POTO, Margherita. Participatory rights in the environmental decision making process and the implementation of the Aarhus Convention: a comparative perspective on the German and the Italian system. Berlin: Duncker \& Humblot, 2015. 
MACHADO, Paulo Afonso Leme. Direito ambiental brasileiro. 21. ed. São Paulo: Malheiros, 2013.

MARTINS, Marcelo Guerra. Internet e Tributação: aspectos relevantes. In: FIORILLO, Celso Antonio Pacheco; MARTINEZ, Regina Célia (Org.). Os 20 anos da internet no Brasil, seus reflexos no Meio ambiente Digital e sua tutela jurídica na sociedade da informação. 2015. Disponível em: <http://portal. fmu.br/mestrado/direito/arquivos/publicacao_livro20Anos.pdf>. Acesso em: 24 abr. 2017.

MAZZUOLI, Valério de Oliveira; AYALA, Patryck de Araujo. Cooperação internacional para a preservação do meio ambiente: o direito brasileiro e a Convenção de Aarhus. Revista de direito ambiental, São Paulo: RT, v. 62, p. 223-266, abr. 2011.

OLIVEIRA FILHO, Gabriel Barbosa Gomes de. Novo Constitucionalismo Latino - Americano: O Estado Moderno em contextos Pluralistas. Revista Culturas Jurídicas, Niterói, v. 1, n. 1, 2014. Disponível em: <http://www.culturasjuridicas.uff.br/index.php/rcj/article/view/41/5>. Acesso em: 24 abr. 2017.

ONU. Declaração Universal dos Direitos do Homem. 10 dez. 1948. Disponível em: <http://unesdoc. unesco.org/images/0013/001394/139423por.pdf>. Acesso em: 24 abr. 2017.

ONU. Carta Mundial para a Natureza (UN Doc. A/RES/37/7). 28 out. 1982. Disponível em: $<$ http://www.meioambiente.pr.gov.br/arquivos/File/agenda21/Carta_Mundial_para_Natureza. pdf>. Acesso em: 24 abr. 2017.

PAROLA, Giulia. O modelo teórico da democracia ambiental: uma introdução à obra In: AVZARADEL, Pedro Curvello Saavedra; PAROLA, Giulia; VAL, Eduardo (Org.). Democracia Ambiental na América Latina: uma abordagem comparada. Rio de Janeiro: Multifoco, 2016.

PAROLA, Giulia. Environmental Democracy at Global Level. London: Versita, $2013 a$.

PAROLA, Giulia. Europe in Green. London: Versita, $2013 b$.

RANGEL, Tauã Lima Verdan. Meio Ambiente Cultural e Internet: O potencial das tecnologias da comunicação para a sustentabilidade na Sociedade da Informação. Âmbito Jurídico, 06 maio 2017. Disponível em: <http://www.egov.ufsc.br/portal/conteudo/o-meio-ambiente-cultural-e-internet-o-potencial-das-tecnologias-da-comunica\%C3\%A7\%C3\%A3o-para > . Acesso em: 24 abr. 2017.

SAMPAIO, Izabel Cristina da Silva. Informação ambiental: a Convenção de Aarhus e seu contributo no âmbito da União Europeia. RIDB, a. 2, n. 12, p. 14233-14298, 2013. Disponível em: <http:// www.cidp.pt/publicacoes/revistas/ridb/2013/12/2013_12_14233_14298.pdf>. Acesso em: 24 abr. 2017.

SILVEIRA. Sérgio Amadeu da. Exclusão digital: a miséria na era da informação. São Paulo: Fundação Perseu Abramo, 2001.

STEC, Stephen; CASEY-LEFKOWITZ, Susan. The Aarhus Convention: an Implementation Guide. E. C. F. Europe: United Nations Publication, 2000. Disponível em: <http://www.unece.org/fileadmin/DAM/env/pp/acig.pdf>. Acesso em: 24 abr. 2017. 
TAVARES, Augusto; MARCACINI, Rosa. Direito e Tecnologia: reflexões sobre os 20 anos de internet no Brasil. In: FIORILLO, Celso Antonio Pacheco, MARTINEZ, Regina Célia (Org.). Os 20 anos da internet no Brasil, seus reflexos no Meio ambiente Digital e sua tutela jurídica na sociedade da informação. 2015. Disponível em: <http://portal.fmu.br/mestrado/direito/arquivos/publicacao_livro20Anos.pdf>. Acesso em: 24 abr. 2017.

Data de submissão: 18 de maio de 2017 Avaliado em: 03 de julho de 2017 (AVALIADOR A) Avaliado em: 01 de agosto de 2017 (AVALIADOR B) Aceito em: 15 de agosto de 2017 
